\title{
Investigation of Factors that Induce Premarital Sexual Intercourse Among Adolescents in Secondary Schools in Nigeria
}

\author{
Babatunde, Ezekiel Olusegun, PhD \\ Institute Of Education, University Of Ibadan, Ibadan. Nigeria
}

Doi:10.19044/esj.2019.v15n7p129～ＵRL:http://dx.doi.org/10.19044/esj.2019.v15n7p129

\begin{abstract}
Adolescence is a period of life that is characterized by dramatic changes in biological processes in physical and social contexts. The period can be demanding and challenging because adolescents are pre-occupied with self- identity, self-image and acceptability in the society as well as selfawareness since the action to be taken is a big part of person's life in the future particularly on whether or not to engage in premarital sexual intercourse. This study investigated factors that induce adolescents to engage in premarital sexual intercourse among secondary school students in Nigeria. The study was guided by three research questions and one hypothesis and adopted survey research design. Multistage sampling technique was used to sample 600 students from all the six geo-political zones in Nigeria. One instrument with reliability coefficient of 0.79 was used for data collection. Descriptive and Inferential statistics was used to analyze the data collected. Finding shows that previous sexual abuse experience (75\%) was the most potent factor that induces premarital sexual intercourse and four of the of the independent variables showed significant contribution to the dependent variable: previous sexual abuse experience $(\beta=.290, \mathrm{p}<.05)$, smoking of prohibited drugs $(\beta=$ $-.345, \mathrm{p}<.05)$, peer influence $(\beta=.225, \mathrm{p}<.05)$, poor housing condition $(\beta=$ $.126, \mathrm{p}<.05)$. It was recommended that adolescents should avoid engaging in premarital sexual intercourse and reduce curiosity about sex.
\end{abstract}

Keywords: Induce, Sexual abuse experience, Premarital sexual intercourse, Adolescent

\section{Introduction}

Adolescence is a period of life characterized by dramatic changes in biological processes as well as physical and social contexts. The period witness physical changes to their bodies, their mental and psychological attitudes as well as their relationship in the society which made them to raise 
issues about their personality and how they fit into the ever changing world around them. Issues such as how they fit into their family, their relationship with friends or peers, with their teachers and other people around them tend to occupy their mind. This time is defined by the age range between 1217 years. Adolescence stage ranges from years of puberty to adulthood. This was approximately divided into three stages referred to as early adolescence (12 - 13 years); middle adolescence (14 to 16 years); and late adolescence, (17 - 21 years). The period of adolescence can be demanding and challenging for young adults as adolescents are more pre-occupied with self- identity, selfimage and acceptability in the society and self- awareness. As a result, they therefore try to discover and solidify their sense of belonging and their social image in any society they find themselves (Hindin \& Hindin (2009). At this stage in life, they were challenged to consider what the effects of their action are. Many factors influence the decision by adolescents on when, whether and how to engage in sexual relationship and activity (Ong, 2009). Pre-marital sex is terminologies which are mostly overheard by people from the adolescents. Some engaged in this act in a casual way and think of its effect after they have committed such action. It is of common knowledge that when a man and woman engaged in sexual intercourse, the result more often than not is coupled with procreation. This will result to pregnancies and for adolescent; this will be an early entrance to the world of motherhood. This study is conducted due to the prevalent of unplanned pregnancy due to premarital sex that is so rampant in our society today. Adolescents who engage in premarital sex face a lot of problems and the effects of premarital sex must be clear to the young ones (Gorne, 2006). The need to discourage them from getting involved at an early age is one of the purposes of this study. This study desires to promote abstinence from sexual intercourse at an early age as this is meant for those who are matured and married as a couple. Some factors that can induce adolescent into premarital intercourse include selfimage, religious inclinations, socio-economic background, media, family values, peer influence, cultural background among others (Ounjit, 2011) However when adolescents tend to abstain from or postpone sexual intercourse, the support from individuals, adult members of the family and teachers may be necessary to ward off peer, media and other societal pressures as adolescents who receive such support take decisions that are less-risky or risk-free (Ounjit, 2011). One of the primary motivations for adolescents is their desire to fit in with their peers (DeCew, 1996). The role of peers and other social actors in neighborhood settings is central to the idea of "pro-early child bearing' communities as young people particularly in deprived areas where opportunities for social mobility are restricted, may be vulnerable to the influence of peers and others in their communities (Anderson, 1991). This type of influence has been described elsewhere in relation to adolescent 
sexual activity and the risk of pregnancy (Brewster, 1994). Individuals can be influenced by their families, peers, neighbours and others in the community. Adolescents who perceive their friends or peers to be sexually active are likely to engage in sexual activity themselves as well as have multiple sex partners (Moore and Chase-Lansdale, 1999; Evans, Dates, \&Schwab, 1992; WHO, 2003). $\quad$ Peer pressure is often used to describe the pressure exerted by a peer group on a person in encouraging him or her to change his or her attitude, behaviour, morals and or values to conform to the group's actions, taste, fashion sense or general outlook on life. A person affected by peer pressure may or may not want to belong to the group. Adolescents may also recognize, dissociate, and thus behave adversely to that group's behaviours. There are two types of peer pressure: positive and negative. Positive peer pressure is when someone tries to help an individual change an attitude for the better while negative peer pressure is the opposite such as pressure on someone to have sex without using a condom, for drugs, popularity, money etc. (Adegoke \& Ayoade, 2007). According to Elliot and Menard (1996) exposure to deviant peers has been linked to increase in a wide range of delinquent behaviours such as drug abuse, covert antisocial behaviour, and violent crimes as well as early and high risk sexual behaviour. Some factors that can induce adolescent into premarital intercourse include self-image, religious inclinations, socio-economic background, media, family values, peer influence, cultural background among others (Massachusetts Department of Education, 2010). However when adolescents tend to abstain from or postpone sexual intercourse, the support from individuals, adult members of the family and teachers may be necessary to ward off peer, media and other societal pressures as adolescents who receive such support take decisions that are less-risky or risk-free (Massachusetts Department of Education, 2010).

One of the primary motivations for adolescents is their desire to fit in with their peers. As such, older adolescents tend to experience tremendous peer pressure. In addition to greater peer pressure, teens experience other new pressures as part of their transition to adolescence. There is the likelihood for adolescents to be more influenced by friends in their local environment than close friends at school (DeCew, 1996). The role of peers and other social actors in neighborhood settings is central to the idea of 'pro-early child bearing' communities as young people - particularly in deprived areas where opportunities for social mobility are restricted-may be vulnerable to the influence of peers and others in their communities (Anderson,1991). This type of influence has been described elsewhere in relation to adolescent sexual activity and the risk of pregnancy (Brewster, 1994). Individuals can be influenced by their families, peers, neighbours and others in the community. Adolescents who perceive their friends or peers to be sexually active are 
likely to engage in sexual activity themselves as well as have multiple sex partners (Moore \& Chase-Lansdale, 1999; Evans et al., 1992). Wong, et al., (2012) advance that among male adolescents, one of the significant factors that is associated to sexual intercourse is lack of confidence to resist peer pressure to engage in sex, and also the perception that one half or more of their friends have already engage in premarital sex. Alo \& Akinde (2010) mentioned that a consensus indicates that peer pressure is a significant predictor of sexual activity (UNICEF, 2001; UNICEF/UNFPA, 2003; Leonard 2005 as cited in Naijanewsreel, 2011). To boost the self-confidence of the children, parents need to support them, assert the beauty of life to ensure their feelings and heighten their morale. It is important that parents lead the direction of the lives of their children so that they will not long for others' company and submit themselves to peers.

Mass media are tools for the transfer of information, concepts and ideas to both general and specific audience. Television is a powerful medium which appeals to large audiences; it reaches people regardless of age, sex, socio-economic background or level of education. In addition, television offers both visual and audio, and it makes dramatic and life-like representations of people and products. Television coverage of public health tends to focus more on issues relating to food items, soaps, oral hygiene, curative medicine and other items. Public health authorities have expressed concern about the influence of the media in promoting false norms about acts of violence, drinking, smoking and sexual behaviour. Rarely is safe sex practice portrayed in the media (Bennet, 2000). Media are a pervasive and ever present entity in the lives of many individuals. It is a strong influence for constructing meaning in our everyday lives. However, because adolescents have not reached the cognitive level to critically analyze and determine reasonable levels of realistic goals, they tend to take at face value every image and scenario portrayed in the media (Hargreaves \& Tiggermann, 2003). Similarly, Murnen and Smolak (2000) have found that television, more than any other form of media, influences adolescent females' attitudes and views about society and social interactions. It is through television that adolescent girls are connected to the expansive social world. Girls watch television to define normal and appropriate roles and behaviour for men and women. This explains why adolescent females look to the media to define their place in the society and help them develop interpersonal skills. In addition to increased violent content in the electronic media, children are today exposed to more adult behaviours like smoking, alcohol consumption, drug use to mention but just a few. Children often copy these behaviours in order to make themselves feel like adults (Gentile, Lynch, Linder, \& Walsh, 2004; WHO, 2012). Watching television, going to the cinema or picking up a magazine to read will show the prominence of sexual issue across the media. Although some 
media incorporate pro-social messages about sex and sexual issues, such as the risks and consequences of unprotected sex, most of the media do not in most cases and whether these messages incorporate positive or negative themes, are seen by many people today as raising legitimate questions about the influence they have on the behaviours and attitudes of adolescent viewers (Kaiser Family Foundation, 2004). The study of Granello (1997) has shown that the influence of the mass media on the adolescent is more than that of the peer group and the school. Because they tend to see most of the things they view as realistic and attainable, adolescent girls are more likely to imitate or emulate the images portrayed in the media.

Gender is an important factor that has been used to explain adolescent behaviour. Studies have shown that gender differences may influence adolescent sexual activity. Emler, Reicher and Ross (1987) suggest that girls may be more susceptible to deviant peer influences than boys. However, other studies indicate that boys are more influenced by same-sex peers, whereas girls are more likely to be influenced by their male friends (Warr, 1996; Simons, Wu, Conger, UNICEF/UNFPA, 2003 \& Lonrez, 1994). Chun Yi, et al., (2012) suspected that the gender differences in the engagement of premarital sex are related to parenting and the family's SES. They found that family with lower SES background tends to perform less parental control. Though issues about drugs and sex are serious matters; however, the family must discuss them in the open and honest ways in order that the adolescents will not seek information from his friends which might not be true and correct (Peer Pressure, 2008).

Adhikari and Tamang (2009) showed that substantial proportions of students who are practicing different religion indulge in sexual activities as well as risky sexual behavior. On the other hand, the religion and culture of the country restrict premarital sex at different degree. Wong, et al., (2012) clearly illustrated that living condition of the respondents in low-cost or poor housing is a significant factor that may make the male adolescents engage in sexual intercourse. This could then be considered as the previous sexual abuse experience of the person (Wong, et al., 2012).

Cooper (2002) supported and articulated that drinking was strongly related to the decision to have sex. Chun Yi, et al., (2012) expressed that among males the use of alcoholic beverages is significantly associated with premarital sex but not for women. Alo and Akinde (2010) assumed that "drugs could induce sexual desire and alcohol use has been identified as factors which may encourage unintended sexual activities" (UNICEF, 2001; Leonard 2005; as cited in Naijanewsreel (2011). The study of Wong, et al., (2010) supported the findings of Alo and Akinde (2010) as cited in Naijanewsreel (2011) when they explain that their girl respondents manifested that when they are under the influence of alcohol or drugs they 
engage in sexual activity. Hindin and Hindin ( 2009) suggest that for male adolescents, abuse of substances, such as drugs, alcohol and tobacco; access to pornographic films and other X-rated materials; having peers who are sexually active; family instability are factors which induce them to engage sexual activities.

Globally, adolescents are becoming more socially and sexually sensitive, mature and active much earlier than parents and other adults around them would have imagined without having requisite psycho-social knowledge that will make them live healthily in the society thereby falling victim of pre-marital sex. This study therefore investigated factors that induce secondary school students into pre-marital sexual intercourse in Nigeria.

\section{Research questions}

The following questions were stated in the study:

1. Is there any difference in

(i) gender

(ii) religion

on inducement of secondary school students premarital sexual intercourse?

2. What are the factors considered as an inducement for pre-marital sexual intercourse among secondary school students in Nigeria?

3. To what extent does the factor predict inducement in pre-marital sexual intercourse among secondary school students in Nigeria?

\section{Research hypotheses}

The following hypotheses were tested.

$\mathrm{Ho}_{1}$ : There is no significance contribution of Peer Influence on secondary school student's pre-marital sexual intercourse.

\section{Methodology}

\section{Research design}

The study adopted the survey research design. This design was used because it is best suited for data collection, organization, presentation and analysis for the purpose of describing the occurrence of an event or phenomenon within a specified group.

\section{Population and sample}

All secondary school students in all the six geo-political zones in Nigeria constituted the population of the study. The sample comprised six hundred (600) respondents selected from the population through multistage sampling technique. The country was stratified into the existing six geopolitical zones and from each zone, a state was randomly selected. From each 
state, five schools were selected giving a total of thirty schools. From each school, simple random sampling was used to select twenty students that participated in the study.

\section{Instrument}

The instrument used for the collection of data was a self-designed questionnaire designed and validated by the researcher. It is divided into two parts Section A and B. Section A of the questionnaire consisted of items requesting personal information from the respondents such as sex, religion and age. Section B consisted of items covering the variables for the study. The item was structured on a 4-point Likert scale of Always (A), Frequently (F), Sometimes (S) and Never (D). A test-retest method was used with Pearson's Product Moment Correlation coefficient of 0.76. Factor - indicators are adapted from the study of Wong, M. et al., (2012). Six hundred (600) questionnaires were administered by the researcher to the respondents with the help of two research assistants. All the administered questionnaires were retrieved the same day thus ensuring $100 \%$ rate of return.

\section{Data analysis}

To analyze the data collected, descriptive statistics of frequency counts and simple percentage were used to analyze the demographic characteristics of respondents while inferential statistics of Multiple Regression was used to test the hypotheses at 0.05 level of significance.

\section{Results}

RQ 1: Is there any difference in

(i) gender

(ii) religion

on inducement of secondary school students premarital sexual intercourse?

Table 1. Frequency Distribution on the Profile of the Respondents by Religion and

\section{Gender}

Gender

Male

Female

Total

\section{Religion}

Protestants

Non-Protestants

Total

$\begin{array}{cr}\text { F } & \text { \% } \\ & \\ 260 & .43 \\ 340 & .57 \\ \mathbf{6 0 0} & \mathbf{1 0 0}\end{array}$

$\begin{array}{rr}334 & .56 \\ 266 & .44 \\ \mathbf{6 0 0} & \mathbf{1 0 0}\end{array}$

Table 1 shows the frequency distribution profile of the respondents by Gender and Religion. From the table, there are 260(43\%) male and 360(57\%) female respondents. This shows that there are more female than male that 
took part in the study. This result showed difference between male and female. Furthermore, the table revealed that majority (56\%) of the participants belongs to the Protestant religion. This may not be unconnected with the spread of the Protestant churches around Nigeria; however, the results of this study showed that there are still many people in this country that belong to non-protestant faith. The result showed difference in the religion being practiced by respondents. The implication of this result is that more female $(57 \%)$ than male $(43 \%)$ were induced to pre-marital sexual intercourse among secondary school students in Nigeria. This is in support of Oladipo-Okorie and Viatonu (2014) that found more female than male being induced to sexual intercourse. The study also corroborates the study of Adhikari and Tamang (2009) who showed that substantial proportions of students who are practicing different religion indulge in sexual activities as well as risky sexual behavior. However, the study did not support the outcome of Villegas, (2011) that opined that their daughters and sons will continue to value chastity and do not follow what the Western societies are doing. The result was not in tandem with the study conducted by Farahani, Cleland and Mehryar (2011) who found that there were college students who did not engage in premarital sex since they wanted to have better opportunities for marriage.

RQ 2: What are the factors perceived as an inducement for pre-marital sexual intercourse among secondary school students in Nigeria?

Table 2: Frequency Distribution on the Factors that induce Premarital Sexual Intercourse

\begin{tabular}{|l|l|l|l|l|l|l|l|l|l|}
\hline \multirow{2}{*}{ Factors } & \multicolumn{2}{l|}{ Always } & \multicolumn{2}{l|}{ Frequently } & \multicolumn{2}{l|}{ Sometimes } & \multicolumn{2}{l|}{ Never } \\
\cline { 2 - 9 } & $\mathrm{F}$ & $\%$ & $\mathrm{~F}$ & $\%$ & $\mathrm{~F}$ & $\%$ & $\mathrm{~F}$ & $\%$ \\
\hline Viewing of pornographic films/videos & 246 & .41 & 210 & .35 & 66 & .11 & 78 & .13 \\
\hline $\begin{array}{l}\text { Lack of confidence to resist peer } \\
\text { pressure or influence by friends }\end{array}$ & 144 & .24 & 330 & .55 & 96 & .16 & 30 & .05 \\
\hline $\begin{array}{l}\text { Sensitivity that their friends had } \\
\text { engaged in sex }\end{array}$ & 198 & .33 & 246 & .41 & 114 & .19 & 42 & .07 \\
\hline $\begin{array}{l}\text { Open-mindedness regarding premarital } \\
\text { sex }\end{array}$ & 90 & .15 & 240 & .40 & 144 & .24 & 126 & .21 \\
\hline Involvement in gang activities & 378 & .63 & 66 & .11 & 84 & .14 & 72 & .12 \\
\hline Drinking of alcoholic beverages & 270 & .45 & 156 & .26 & 96 & .16 & 78 & .13 \\
\hline Smoking of prohibited drugs & 408 & .68 & 60 & .10 & 72 & .12 & 60 & .10 \\
\hline $\begin{array}{l}\text { Living in low-cost housing or poor } \\
\text { housing condition }\end{array}$ & 336 & .56 & 138 & .23 & 84 & .14 & 42 & .07 \\
\hline Previous sexual abuse experience & 450 & .75 & 72 & .12 & 60 & .10 & 18 & .03 \\
\hline
\end{tabular}

*Factor - indicators are adapted from the study of Wong, M. et al., (2012).

Table 2 presented the frequency distribution on the factors that induce premarital sexual intercourse among secondary school students in Nigeria. From the table, it was evident that previous sexual abuse experience (75\%) is 
the most potent factor that induces premarital sexual intercourse among secondary school students in Nigeria. This is followed by smoking of prohibited drugs (68\%), involvement in gang activities (63\%), living in poor housing condition (56\%) and drinking of alcoholic beverages (45\%). The result shows that all the five factors were the reasons why they are induced to premarital sexual intercourse. Viewing of pornographic films/videos (41\%) was moderately high and could also be a factor of inducement. This result is not in agreement with the report of Oladipo-Okorie and Viatonu (2014) stating that the five factors were not the reasons why they engaged in premarital sex. In addition, the result agreed with Farahani, Cleland and Mehryar (2011) who found that living with single parents in some cases resulted to a distorted family relationships and family dysfunction. Moreover, the result support the study of Wong, Kum-Wah Chan, Koh, Tan, Lim, Emmanuel, and Bishop (2012) which suggests that pornography is the strongest factor that tempt the male youth to premarital sex. Furthermore, the result is in agreement with Alo \& Akinde (2010) that mentioned that a consensus indicates that peer pressure is a significant predictor of sexual activity. The result also corroborated the report of Gorne (2006) who found that the use of drugs and drinking of alcoholic beverages more frequently among college students could be influenced by the peers and are more likely to engage in sex before marriage.

RQ 3: To what extent does the factor predict inducement in premarital sexual intercourse among secondary school students in Nigeria?

Table 3a: Regression Analysis of the independent variables on Premarital Sexual

Intercourse

\begin{tabular}{|c|c|c|c|c|c|c|}
\hline $\mathbf{R}$ & \multicolumn{3}{|c|}{ R Square } & $\begin{array}{c}\text { Adjusted } \\
\text { R } \\
\text { Square } \\
\end{array}$ & \multicolumn{2}{|c|}{$\begin{array}{l}\text { Std. Error of the } \\
\text { Estimate }\end{array}$} \\
\hline .421 & \multicolumn{3}{|c|}{.175} & .175 & \multicolumn{2}{|c|}{4.8811} \\
\hline \multicolumn{7}{|c|}{$A N O V A$} \\
\hline Model & $\begin{array}{c}\text { Sumof } \\
\text { Squares }\end{array}$ & DF & $\begin{array}{c}\text { Mean } \\
\text { Square }\end{array}$ & $\mathbf{F}$ & Sig. & Remark \\
\hline $\begin{array}{c}\text { Regression } \\
\text { Residual } \\
\text { Total }\end{array}$ & $\begin{array}{c}5587.667 \\
25873.914 \\
31461.580\end{array}$ & $\begin{array}{c}9 \\
591 \\
600\end{array}$ & $\begin{array}{c}1396.917 \\
23.825\end{array}$ & 58.632 & .000 & Sig. \\
\hline
\end{tabular}


Table 3b: Model Analysis of the independent variables on premarital sexual intercourse

\begin{tabular}{|c|c|c|c|c|c|c|}
\hline \multirow[t]{2}{*}{ Model } & \multicolumn{2}{|c|}{$\begin{array}{l}\text { Unstandardized } \\
\text { Coefficient }\end{array}$} & \multirow{2}{*}{$\begin{array}{l}\text { Standardize } \\
\mathrm{d} \\
\text { Coefficient } \\
\text { Beta } \\
\text { Contribution }\end{array}$} & \multirow[t]{2}{*}{$\mathrm{T}$} & \multirow[t]{2}{*}{ Sig. } & \multirow[t]{2}{*}{ Remark } \\
\hline & B & $\begin{array}{l}\text { Std. } \\
\text { Error }\end{array}$ & & & & \\
\hline (Constant) & 9.945 & & & 10.084 & .000 & Sig \\
\hline $\begin{array}{c}\text { Prev sexual abuse } \\
\text { experience }\end{array}$ & .161 & .986 & 290 & 8.989 & 000 & Sia \\
\hline Smoking of & -.231 & .010 & -.345 & -10.080 & .000 & Sig \\
\hline prohibited drugs & .131 & .023 & .225 & 6.782 & .000 & Sig \\
\hline $\begin{array}{l}\text { Peer influence } \\
\text { Poor housing } \\
\text { condition }\end{array}$ & 9.662E-02 & $\begin{array}{l}.020 \\
.026\end{array}$ & .126 & 3.757 & .000 & Sig \\
\hline
\end{tabular}

Table 4a shows the composite contribution of the independent variables to Premarital Sexual Intercourse. The table revealed a correlation coefficient $\mathrm{R}=.421$ and $\mathrm{R}^{2}$ of .175 . The regression analysis shows that $17.5 \%$ of the variance was accounted for by the predictor variables when taken together. From the table, the analysis of variance (ANOVA) for the regression yielded an F-ratio of 58.632 (significant at 0.05 level). This implies that there was a significant contribution of the independent variables to the dependent variable and that other variables not included in this model may have accounted for the remaining variance.

Table $9 \mathrm{~b}$ reveals relative contribution of each of the independent variables to the dependent variable, previous sexual abuse experience $(\beta=$ $.290, \mathrm{p}<.05)$, smoking of prohibited drugs $(\beta=-.345, \mathrm{p}<.05)$, peer influence $(\beta=.225, \mathrm{p}<.05)$, poor housing condition $(\beta=.126, \mathrm{p}<.05)$. The results showed that all the independent variables: previous sexual abuse experience, peer influence, smoking of prohibited drugs and poor housing condition were all significant. The extent to which each of the independent variables contributed to the prediction is shown by F-ratio values in table 9a as associated with the different variables shown in Table 9b. Tables 9a and b reveal that the composite effect and the relative contribution of each of the independent variables are significant. This showed that previous sexual experience, peer influence; poor housing condition and smoking of prohibited drugs were significant in predicting premarital sexual intercourse among secondary school students in Nigeria. Multiple regressions result $\mathrm{R}^{2}=.175$ account for about $17.5 \%$ of the variance in premarital sexual intercourse among secondary school students in Nigeria.

From the table, it was evident that the F-ratio of 58.632 indicated that $\mathrm{R}^{2}$ value was not due to chance. It can be concluded from the result shown in the table that the joint effect of the previous sexual abuse experience, peer 
influence, smoking of prohibited drugs and poor housing condition on premarital sexual intercourse among secondary school students in Nigeria was significant. This result presented in the table can favourably induce premarital sexual intercourse among secondary school students in Nigeria.

Table 4: Linear Correlation Coefficient Showing Relationship between Peer influence and premarital sexual intercourse among secondary school students

\begin{tabular}{|l|l|l|l|l|l|l|}
\hline Variable & Mean & $\begin{array}{l}\text { Std. } \\
\text { Dev. }\end{array}$ & $\mathrm{N}$ & $\mathrm{R}$ & $\mathrm{P}$ & Remark \\
\hline Peer Influence & 48.6975 & 9.6905 & 1091 & $.284^{*}$ & .000 & Sig. \\
$\begin{array}{l}\text { Premarital Sexual } \\
\text { intercourse }\end{array}$ & 20.8891 & 5.3725 & & & \\
\hline
\end{tabular}

* Sig. at 0.05 level

Table 4 showed a significant relationship between peer influence and premarital sexual intercourse $\left(r=.284^{*}, \mathrm{~N}=600, \mathrm{p}<.05\right)$. The null hypothesis is accepted. This finding indicated that peer influence induced premarital sexual intercourse. Male genders are extra exposed to premarital intercourse than female because of the urge to gain skill and sexual contentment. Involvement in many bedmates at the same time is seen as ego among colleagues. As a result, both male and female experience sexual behavior differently which made them vulnerable to reproductive health risks.

\section{Conclusion and Recommendations}

Many factors influence the decision by adolescents on when, whether and how to engage in sexual relationship and activity. One of the important details in life that extremely need prudent and careful decision by adolescents is whether to engage or not to engage in premarital sexual intercourse. The study revealed that more female than male was induced to pre-marital sexual intercourse among secondary school students in Nigeria. Moreover, the study showed that the five factors (previous sexual abuse experience, smoking of prohibited drugs, involvement in gang activities, living in poor housing condition and drinking of alcoholic beverages) were the reasons that induce premarital sexual intercourse among secondary school students in Nigeria and were also significant in predicting pre-marital sexual intercourse. Social economic status of a family determines to a large extent the type of accommodation such family will be living hence, having a poor housing condition. This experience could expose adolescents to sexual abuse; however, at the perception by the participants of this study, it was considered by them as the most vital factor to engage premarital sexual intercourse. The composite effect and the relative contribution of each of the independent variables are also significant. On the other hand, in the present days, even if the adolescents has no involvement in gang activities, do not drink alcoholic 
beverages, or do not take prohibited drugs there is still a chance that these factors could push them to engage in premarital sexual intercourse. Therefore, it is essential that proactive step be taken in order to curb the incidence of premarital sexual intercourse among secondary school students in Nigeria.

In view of the result of this study, the following recommendations were made:

1. Adolescent should take the responsibility of restricting themselves access to pornographic movies as well as friends they associate with.

2. Adolescents should avoid engaging in premarital sexual intercourse and reduce curiosity about sex.

3. Conducive living accommodation should be provided to avoid sexual abuse among secondary school students

4. Smoking and use of drug should be prohibited among secondary school students so as to avoid being induced to premarital sexual intercourse.

\section{References:}

1. Adegoke, A.A. and Ayoade, C. A. 2007. Relationship among leisure, social self-image, peer pressure and at risk behaviours of adolescents. Journal of psychology on Africa, Vol. 17 Nos. 1\&2, pp.73 -78.

2. Adhikari, R., \& Tamang, J. (2009). Premarital sexual behavior among male college students of Kathmandu, Nepal. doi: 10.1186/1471-24589-241. Retrieved March 27, 2013 from http://www.ncbi.nlm.nih.gov/pmc/articles/PMC2717085/

3. Alo, O. A., and \& Akinde, I. S. 2010. Premarital sexual activities in an urban society of Southwest-Nigeria. Journal of Medical Humanities and Social Studies of Science and Technology, 2, 1-16.5

4. Anderson, E. 1991, "Neighbourhood effects on teenage pregnancy", In C .Jencks and P. E. Peterson (Eds). The urban underclass, Washington DC. The Brookings Institute.

5. Bennet, A. 2000. "Popular music and youth culture: music, identity and place”, London: St. Martin's Press.

6. Bocar Anna and Biong Corazen, (2014).

7. Brewster, K. 1994. "Neighbourhood context and the transition to sexual activity among young black women”, Demography, Vol. 31, pp. $603-614$.

8. Chun Yi, C., Ksobiech, K., \& Chiao, C. (2012). Exploring the relationship between premarital sex and cigarette/alcohol use among college students in Taiwan: A cohort study. Retrieved March 27, 2013 from http://www.biomedcentral.com/1471-2458/12/527

9. Cooper, L. (2002). Alcohol use and risky sexual behavior among college students and youth: Evaluating the evidence. Journal of Studies on Alcohol Supplement. Department of Psychology, 210 
McAlester Hall, University of Missouri-Columbia, Columbia, Missouri 65211 Retrieved March 27, 2013 from http://www.collegedrinkingprevention.gov/Supporting Research/Journal/cooper.aspx

10. DeCew, F. 1996. “Tailor messages to reach subgroups”, Strategy, July 8.

11. Elliot, D.S. and Menard, S. (1996). Deliquent friends and delinquent behaviour: Temporal and development patterns, in Hawkins, J. (ed) Delinquency and crime: current theories. Cambridge Criminology series. New York: Cambridge University press.

12. Emler, N., Reicher, S. and Ross, A. 1987. "The social context of delinquent conduct”, Journal of child psychology and psychiatry, Vol. 28, pp.99-109.

13. Evans, W.N., Dates, W.E. and Schwab, R.M. (1992), "Measuring peer-group effects: a study of teenage behavior", Journal of Political Economy, Vol. 100 No. 5, pp. 966 -991.

14. Farahani, F., John Cleland, J., \& Mehryar, A. (2011). Associations between family factors and premarital heterosexual relationships among female college students in Tehran. International Perspective on Sexual and Reproductive Health Volume 37, Number 1,

15. March 2011. Retrieved March 30, 2013 from http://www.guttmacher.org/pubs/ journals/3703011.html

16. Gentile, D.A., Lynch, P., Linder, J. and Walsh, D. (2004). The effect of violent video game habits on adolescent, hostility, aggressive behaviours and school performance”, Journal of Adolescence, Vol. 27, pp. 5-22.

17. Gorne, E. (2006) Teenage pregnancies and premarital sex alarming in Southern Leyte. Retrieved July 15, 2010 from http://www.Samarnews.com/news2006/oct/f862.htm.

18. Granello, D. H. (1997). "Using Beverly Hills explore developmental issues in female adolescents”, Youth and Society, Vol. 29 No1, pp. 2454

19. Hargreaves, D. and Tiggermann, M. (2003). The effect of "thin ideal" television commercial on body dissatisfaction and schema activation during early adolescence”, Journal of Youth and Adolescence, Vol. 32 No. 5, pp. 367-373.

20. Hindin, J., \& Hindin, M. (2009).Premarital romantic partnerships: Attitudes and sexual experiences of youth in Delhi, India. International perspective on sexual and reproductive health. Volume 35, Number 2, June 2009 http://www.guttmacher.org/pubs/journals/3509709.html. DOI: $10.1363 / 3509709$ 
21. Kaiser Family Foundation 2004. "Survey snapshot: Teens sex, and TV Online”, Available at http://www.kff.org.

22. Leonard, S. 2005. Why gender matters? Great Britain: Doubleday Books.

23. Massachusetts Department of Education (2010). "Sexuality and reproductive health”, Online, Available at http://www.doe.mass.educ retrieval on 01/11/2011.

24. Moore, M.R. and Chase-Lansdale, P. L. 1999. Sexual intercourse and pregnancy among African-American adolescent girls in high-poverty neighbourhoods: the role of family and perceived community environment”, JCPR working paper 117, Northwestern.

25. Murnen, S.K. and Smolak, L. 2000. The experience of sexual harassment among grade school students: Early socialization of female subordination?”, Sex Roles, Vol. 43 Nos. 1\&2, pp.1-17.

26. Naijanewsreel. (2011).Premarital sex and school dropout. Retrieved June $\quad 10, \quad 2013 \quad$ from http://justcreativedesignfitnesstips.blogspot.com/2011/11/pre-marital-sex-and-school-dropout.html

27. Oladipupo-Okorie, B.O. and Viatonu, O. (2014), “Influence of Family Characteristics and Cultural norms on Pre-marital sex among secondary school students in Ojo Local Government Area of Lagos State, Nigeria”, European Scientific Journal, Vol. 10 No. 5, pp. 231242.

28. Ong, C. (2009). Teenage pregnancy on the rise in the Philippines. MediaCorp Pte Ltd. Retrieved July 1, 2012 from http://www.channelnewsasia.com/stories/southeastasia/view/430635 /1/.html

29. Ounjit, W. (2011). Becoming pregnant before marriage: The value of sex without forgiveness. International Proceedings of Economics Development \& Research. Vol. 5 Issue 1. Academic Journal. Retrieved Spetember 9, 2012. From http://connection.ebscohost.com/c/articles/74744702/becomingpregnant-before-marriage-value-sex-without-forgiveness

30. Peer pressure. (2008) All Psychology Careers.com. Retrieved March 27, 2013 from http://www.allpsychologycareers.com/topics/peerpressure.html

31. Simons, R.L., Wu, C., Conger, R.D. and Lorenz, F.O. 1994. Two routes to delinquency: Differences between early and late starters in the impact of parenting and deviant peers”, Criminology, Vol. 32, pp. 247-275.

32. UNESCO/UNFPA. (2003). State of world population 2003. Making 1 billion count: investing in adolescents' health and rights. New York, 
UNFPA. http://www.unfpa.org/swp/2003/; accessed 30 March 2004.UNFPA annual report 2003 (www.unfpa.org )

33. UNICEF 2001. A league table teenage births in rich nations. Innocent Report Card No. 3.

34. Warr, M. 1996. Organization and Investigation in delinquent groups", Criminology, Vol. 34, pp.11-37.

35. Wiltse, L. (2009).Teenage pregnancy in Manila, Philippines. Retrieved July $1, \quad 2012$ from http:/lab.colorsmagazine.com/teenagers/contributed/teenagepregnancy-manila-philippines

36. Wong, M., Kum-Wah Chan, R., Koh, D., Tan, H., Lim, F., Emmanuel, S., Bishop, G. (2012). Premarital sexual intercourse among adolescents in an Asian country: Multilevel ecological factors. Retrieved July 1, 2012 from http://pediatrics.aappublications.org/content/ 124/1/e44.abstract

37. WHO (2003). Unsafe abortion: global and regional estimates of incidence of and mortality due to unsafe abortion with a listing of available country data, Geneva.

38. WHO (2012). From Evidence to Policy: Expanding access to Contraceptive services for adolescents. World Health Organization, Geneva. 